\title{
Número de colheitas e comparação de genótipos de tomateiro cultivados em estufa de plástico
}

\author{
Alberto Cargnelutti Filho(1), Bernadete Radin(1), Ronaldo Matzenauer ${ }^{(1)}$ e Lindolfo Storck ${ }^{(2)}$ \\ (1)Fundação Estadual de Pesquisa Agropecuária, Rua Gonçalves Dias, 570, Bairro Menino Deus, CEP 90130-060 Porto Alegre, RS. E-mail: \\ alberto-cargnelutti@fepagro.rs.gov.br (2)Universidade Federal de Santa Maria, Dep. de Fitotecnia, Av. Roraima, s/no, Camobi, CEP $97105-900$ \\ Santa Maria, RS. E-mail: storck@ccr.ufsm.br
}

\begin{abstract}
Resumo - O objetivo deste trabalho foi determinar o número de colheitas necessárias à predição do desempenho de genótipos de tomateiro (Lycopersicon esculentum) submetidos ao cultivo em ambiente protegido. Os genótipos Empire, Fanny, Floradade e Olympo foram transplantados em 3/10/2002 (primeira época), sendo realizadas 11 colheitas, e os genótipos Empire, Rodas, Floradade e Olympo foram transplantados em 28/2/2003 (segunda época), sendo efetuadas 14 colheitas. As colheitas foram realizadas em intervalos de três a quatro dias. As avaliações foram constituídas por massa de frutos bons (MFB), número de frutos bons (NFB), relação MFB/NFB, massa de frutos danificados (MFD), número de frutos danificados (NFD) e relação MFD/NFD. As estimativas dos coeficientes de repetibilidade foram calculadas por três métodos - análise da variância, componentes principais e análise estrutural. Até sete colheitas, aproximadamente a primeira metade, independentemente da época de cultivo, é possível identificar genótipos superiores em relação às características de produção de tomate, com $90 \%$ de exatidão no prognóstico de seu valor real.
\end{abstract}

Termos para indexação: Lycopersicon esculentum, repetibilidade, seleção, cultivo protegido.

\section{Number of harvests and comparison of tomato genotypes cultivated under plastic greenhouse}

\begin{abstract}
The objective of this study was to determine the number of harvests necessary to predict the performance of tomato (Lycopersicon esculentum) genotypes under greenhouse conditions. The genotypes Empire, Fanny, Floradade and Olympo were transplanted on October 3, 2002 and submitted to 11 harvests. The genotypes Empire, Rodas, Floradade and Olympo were transplanted on February 28, 2003 and submitted to 14 harvests. Harvests were carried through in three intervals of four days. The mass and the number of fruits and the ratio mass/number were evaluated for commercial and discarded fruits. Repeatability estimates were obtained through variance, structural, and principal component analysis. Seven harvests are sufficient to identify superior genotypes for all characteristics, with $90 \%$ accuracy of the real value, in both grown conditions.
\end{abstract}

Index terms: Lycopersicon esculentum, repeatability, selection, protecting culture.

\section{Introdução}

O tomate é considerado a mais importante hortaliça produzida no Brasil, sendo utilizada na dieta alimentar como fonte de vitaminas e minerais. Por sua importância econômica, tem sido uma das espécies mais cultivadas em ambiente de estufa. Sob o aspecto social, esse tipo de cultivo assume grande relevância por ser desenvolvido em pequenas propriedades e utilizar mão-de-obra familiar. No entanto, os custos de produção são elevados e, por isso, devem ser compensados com maior produtividade e qualidade dos produtos (Radin, 2002).

Para identificar genótipos de tomateiro (Lycopersicon esculentum) mais adaptados a um determinado ambi- ente, são necessárias avaliações periódicas das colheitas, de modo a mensurar o comportamento das principais características produtivas, podendo-se estimar a variabilidade genotípica e a repetibilidade do desempenho de cada genótipo. Ao final da última colheita, registram-se todas as informações relativas aos componentes de produtividade do tomateiro. No entanto, fatores climáticos adversos e roubos podem ocorrer antes do término da produção de determinado experimento, podendo impedir a sua concretização. Portanto, a delimitação do número de avaliações (colheitas) necessárias para a estimativa das diferenças entre os materiais genotípicos poderá auxiliar na seleção de genótipos de tomateiro geneticamente superiores, caso esses even- 
tos ocorram antes da última colheita e após o número mínimo de colheitas.

Nos ensaios envolvendo progênies avaliadas em sucessivas colheitas, é possível estimar os coeficientes de repetibilidade das variáveis estudadas, ou seja, a probabilidade de aquele resultado se repetir em avaliações futuras e, também, o número de observações fenotípicas necessárias de determinado caráter que devem ser realizadas em cada indivíduo para que a discriminação ou seleção entre os genótipos seja feita com certo grau de confiabilidade e economia de tempo e mão-de-obra (Cornacchia et al., 1995; Cruz \& Regazzi, 1997; Pereira et al., 1998; Ferreira et al., 1999).

O coeficiente de repetibilidade de uma característica pode ser conceituado, estatisticamente, como a correlação entre as medidas em um mesmo indivíduo (Abeywardena, 1972; Kempthorne, 1973; Cruz \& Regazzi, 1997), cujas avaliações foram repetidas no tempo ou no espaço, sendo que a repetibilidade expressa a proporção da variância total, decorrente das variações proporcionadas pelo genótipo e das alterações permanentes atribuídas ao ambiente comum. Além disso, a repetibilidade expressa o valor máximo que a herdabilidade pode atingir, pois representa a proporção da variância fenotípica, que é atribuída às diferenças genéticas, confundidas com os efeitos permanentes que atuam no genótipo. Segundo Cruz \& Regazzi (1997), o número de medições necessárias na previsão do valor real do indivíduo é aquele em que os efeitos temporários do ambiente sobre o caráter tendem a se cancelar.

Valores altos de estimativas de repetibilidade em determinado caráter indicam que é viável predizer o valor real do indivíduo utilizando-se um número relativamente pequeno de medições (Cruz \& Regazzi, 1997), ocorrendo o inverso quando a repetibilidade é baixa.

Métodos para a obtenção de estimativas de coeficiente de repetibilidade, como o da análise de variância, dos componentes principais (Abeywardena, 1972; Rutledge, 1974) e o da análise estrutural (Mansour et al., 1981), têm sido usados em diferentes culturas, como a seringueira (Vasconcellos et al., 1985), o pinus (Cornacchia et al., 1995), o cupuaçuzeiro (Costa et al., 1997), a alfafa (Pereira et al., 1998; Ferreira et al., 1999), o cacau (Dias \& Kageyama, 1998; Carvalho, 1999), o cajueiro-anão-precoce (Cavalcanti et al., 2000), a aceroleira (Lopes et al., 2001), o açaizeiro (Oliveira \& Fernandes, 2001) e o capim-elefante (Shimoya et al., 2002).

Pesq. agropec. bras., Brasília, v.39, n.10, p.953-959, out. 2004
O objetivo deste trabalho foi determinar o número de medições necessárias à predição do desempenho de genótipos de tomateiro, submetidos ao cultivo em ambiente protegido.

\section{Material e Métodos}

Foram avaliados quatro genótipos de tomateiro, Empire, Fanny, Floradade, Olympo, na primeira época (transplante em 3/10/2002) e quatro genótipos, Empire, Rodas, Floradade, Olympo, na segunda época (transplante em 28/2/2003), cultivados em estufa, no Centro de Pesquisa da Fundação Estadual de Pesquisa Agropecuária (Fepagro) em Eldorado do Sul, Rio Grande do Sul (latitude 305'S, longitude 5139' W, $10 \mathrm{~m}$ de altitude). Utilizou-se uma estufa modelo pampeana com cobertura em arco e dimensões de 10x24 m, com pé-direito de 3,0 $\mathrm{m}$ e altura máxima de 4,5 $\mathrm{m}$ na parte central.

Os dois experimentos foram conduzidos no delineamento em blocos ao acaso, com oito repetições. As parcelas mediam $1,25 \times 5,1 \mathrm{~m}$, com 17 plantas espaçadas $0,3 \mathrm{~m}$ entre si na linha e 1,25 m entrelinhas. As sementes foram colocadas em bandejas de poliestireno com 128 células, e as mudas foram transplantadas quando possuíam quatro folhas definitivas. Realizou-se uma única poda para a retirada dos brotos abaixo do primeiro rácimo floral, porque os genótipos são de hábito de crescimento determinado. As avaliações (colheitas) foram realizadas de 16/12/2002 a 20/1/2003 e de 25/5/2003 a 11/7/2003, com intervalos de tempo que variaram entre três a quatro dias, totalizando 11 e 14 colheitas, na primeira e segunda épocas, respectivamente.

Avaliaram-se as variáveis massa de frutos bons (MFB), número de frutos bons (NFB), relação MFB/NFB (MNB), massa de frutos danificados (MFD), número de frutos danificados (NFD) e relação MFD/NFD (MND) de cada genótipo de tomateiro, em cada colheita. Os frutos danificados caracterizaram-se por serem não-comerciais, o que abrange os refugos e aqueles atacados por pragas e doenças. Na primeira época de cultivo não houve frutos danificados.

Realizou-se a análise da variância a partir da média das repetições em cada época de cultivo, utilizando-se o modelo estatístico reduzido com dois fatores de variação $\left(Y_{i j}=m+G_{i}+C_{j}+e_{i j}\right)$, em que, $Y_{i j}$ é a média do i-ésimo genótipo na j-ésima colheita; $m$ é a média geral; $\mathrm{G}_{\mathrm{i}}$ é o efeito aleatório do i-ésimo genótipo sob influência do ambiente permanente (colheita) ( $i=1,2, \ldots, 4$ genótipo); $\mathrm{C}_{\mathrm{j}}$ é o efeito fixo do ambiente temporário na j-ésima 
colheita $\left(j=1,2, \ldots, 14\right.$ colheita); $e_{i j}$ é o efeito aleatório que envolve outras causas de variação não incluídas no modelo.

Realizou-se também a análise da variância individual para cada colheita de cada época de cultivo. Foram calculadas as estatísticas média geral e o coeficiente de variação experimental, que foram utilizados como variáveis dependentes na análise de regressão com a variável independente (número da colheita), com a finalidade de verificar o comportamento dessas estatísticas durante o período de colheita.

As estimativas dos coeficientes de repetibilidade $(\hat{\mathbf{r}})$ foram calculadas pelos métodos da análise de variância (ANOVA), dos componentes principais com base nas matrizes de correlações $\left(\mathrm{CP}_{\text {cor }}\right)$ e de variâncias e covariâncias fenotípicas $\left(\mathrm{CP}_{\text {cov }}\right)$ e da análise estrutural, com base nas matrizes de correlações intraclasse $\left(\mathrm{AE}_{\mathrm{cor}}\right)$ e de variâncias e covariâncias $\left(\mathrm{AE}_{\mathrm{cov}}\right)$. $\mathrm{O}$ número mínimo de medições necessárias para predizer o valor real dos indivíduos, com base nos coeficientes de determinação $\left(\mathrm{R}^{2}\right)$ preestabelecidos $(0,80,0,85,0,90,0,95$ e 0,99$)$, foi obtido conforme Cruz \& Regazzi (1997). As análises estatísticas foram realizadas utilizando-se o programa computacional GENES (Cruz, 2001).

\section{Resultados e Discussão}

Com exceção da massa de frutos bons (MFB) na primeira época de cultivo e a massa de frutos danifica- dos (MFD) na segunda época, as demais variáveis apresentaram efeito de genótipos significativo, indicando a possibilidade de identificação de genótipos superiores por meio da heterogeneidade do material genético (Tabela 1). O coeficiente de variação, na primeira época de cultivo, oscilou de $10,77 \%$ (MNB) a $39,44 \%$ (NFB) e, na segunda, entre 17,97\% (MNB) e 37,03\% (NFD). De modo geral, as variáveis NFB, nas duas épocas de cultivo, e NFD na segunda, apresentaram menor precisão experimental em relação às demais variáveis.

A análise da variância individual, por colheita, revelou menor precisão experimental - maior coeficiente de variação experimental - nas primeiras e últimas colheitas de todas as características nas duas épocas de cultivo (Figura 1). A maior variabilidade entre as repetições nessas colheitas, possivelmente, pode ser explicada pelo fato de o início e o término da emissão de frutos não serem uniformes entre as plantas. Sendo assim, provavelmente as plantas que iniciam a emissão de frutos antes encerram a produção mais cedo. Como o intervalo entre colheitas foi de três a quatro dias, é difícil haver coincidência entre as primeiras e últimas colheitas. Houve comportamento quadrático do desempenho de todas as variáveis, em ambas épocas de cultivo, ao longo das colheitas, mostrando picos máximos de massa de frutos, número de frutos e relação massa por fruto, tanto em frutos bons como nos danificados nas colheitas intermediárias, coincidindo com colheitas de menor coeficiente de variação experimental, ou seja, maior preci-

Tabela 1. Análise da variância (modelo reduzido) dos caracteres massa de frutos bons (MFB), número de frutos bons (NFB), relação MFB/NFB (MNB), massa de frutos danificados (MFD), número de frutos danificados (NFD) e relação MFD/NFD (MND) de genótipos de tomateiro avaliados em duas épocas de cultivo.

\begin{tabular}{|c|c|c|c|c|c|c|c|}
\hline \multirow[t]{2}{*}{ Fonte de variação } & \multirow[t]{2}{*}{ GL } & \multicolumn{6}{|c|}{ Quadrado médio } \\
\hline & & $\begin{array}{l}\text { MFB } \\
\left(\mathrm{g} \mathrm{m}^{-2}\right)\end{array}$ & $\begin{array}{c}\mathrm{NFB} \\
\text { (frutos } \mathrm{m}^{-2} \text { ) }\end{array}$ & $\begin{array}{c}\text { MNB } \\
\left(\text { g fruto }^{-1}\right)\end{array}$ & $\begin{array}{l}\text { MFD } \\
\left(\mathrm{g} \mathrm{m}^{-2}\right)\end{array}$ & $\begin{array}{c}\text { NFD } \\
\left(\text { frutos } \mathrm{m}^{-2} \text { ) }\right.\end{array}$ & $\begin{array}{c}\text { MND } \\
\left(\mathrm{g} \mathrm{fruto}^{-1}\right)\end{array}$ \\
\hline & & \multicolumn{6}{|c|}{ Primeira época (transplante em 3/10/2002) } \\
\hline Colheitas & 10 & $701.189,8428$ & 36,5459 & $1.481,2078$ & $-(1)$ & - & - \\
\hline Genótipos & 3 & $108.421,6673^{\mathrm{ns}}$ & $23,4607 *$ & $9.193,5345^{*}$ & - & - & - \\
\hline Resíduo & 30 & $64.016,3559$ & 4,7015 & 226,1171 & - & - & - \\
\hline Média & & 731,568 & 5,498 & 139,570 & - & - & - \\
\hline \multirow[t]{2}{*}{$\mathrm{CV}(\%)$} & & 34,59 & 39,44 & 10,77 & - & - & - \\
\hline & & \multicolumn{6}{|c|}{ Segunda época (transplante em $28 / 2 / 2003$ ) } \\
\hline Colheitas & 13 & $282.587,5445$ & 10,3308 & $3.143,0416$ & $11.993,4889$ & 0,8817 & $7.516,4019$ \\
\hline Genótipos & 3 & $75.460,2202 *$ & $1,8496^{*}$ & $20.531,2131 *$ & $188,0664^{\mathrm{ns}}$ & s $0,1264 *$ & $2.979,0223 *$ \\
\hline Resíduo & 39 & $10.815,0641$ & 0,6314 & 598,4546 & 241,7233 & 0,0317 & 402,6610 \\
\hline Média & & 382,436 & 2,622 & 136,167 & 51,550 & 0,481 & 70,002 \\
\hline $\mathrm{CV}(\%)$ & & 27,19 & 30,31 & 17,97 & 30,16 & 37,03 & 28,67 \\
\hline
\end{tabular}

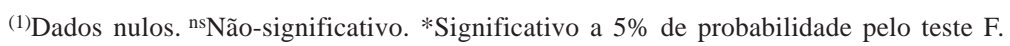


são (Figura 1). Pode-se inferir que as colheitas intermediárias seriam as mais eficientes na comparação entre as cultivares. No entanto, as colheitas iniciais e finais não devem ser desconsideradas, por fazerem parte da produção total de cada genótipo.

$\mathrm{Na}$ segunda época de cultivo, os genótipos Empire, Floradade e Olympo apresentaram média geral inferior à primeira época em relação aos frutos bons nas variáveis MFB, NFB e MNB (Tabela 2). Além disso, na segunda época houve presença de frutos danificados, indicando desempenho inferior dos genótipos de tomateiro, se comparado com a primeira época. Este fato pode ser atribuído, provavelmente, a temperaturas menores e à maior incidência de moléstias. No total das 11 colhei-

Primeira época (transplante 3/10/2002)
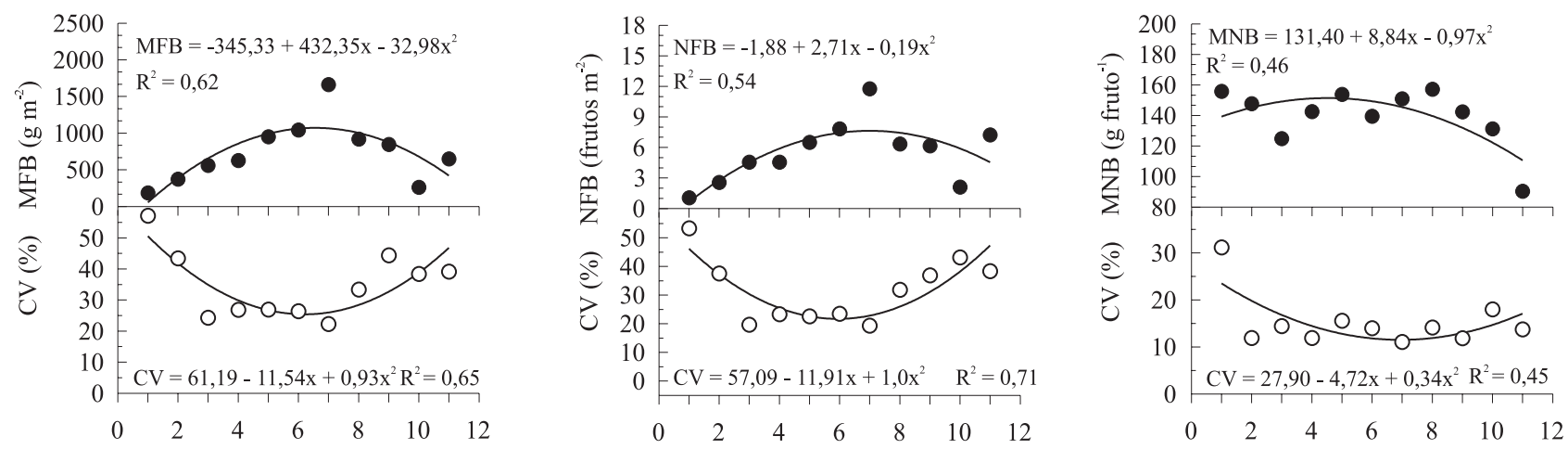

Segunda época (transplante 28/2/2003)


Figura 1. Coeficiente de variação experimental (CV) e média dos caracteres massa de frutos bons (MFB), número de frutos bons (NFB), relação MFB/NFB (MNB), massa de frutos danificados (MFD), número de frutos danificados (NFD) e relação MFD/NFD (MND) de genótipos de tomateiro em cada colheita, avaliados em duas épocas de cultivo. 
tas da primeira época, a massa de frutos bons (MFB) variou de 6,497 $\mathrm{kg} \mathrm{m}^{-2}$ (genótipo Olympo) a 9,023 $\mathrm{kg} \mathrm{m}^{-2}$ (genótipo Empire), com média de $8,047 \mathrm{~kg} \mathrm{~m}^{-2}$, ao passo que, na segunda época, a produção de frutos bons foi igual a 66,5\% da produção da primeira época, com valores oscilando entre $3,978 \mathrm{~kg} \mathrm{~m}^{-2}$ (genótipo Floradade) e $6,397 \mathrm{~kg} \mathrm{~m}^{-2}$ (genótipo Rodas), com média de $5,354 \mathrm{~kg} \mathrm{~m}^{-2}$.

A maioria das variáveis correlacionaram-se linearmente, indicando possibilidades de seleção de genótipos superiores de modo indireto, mediante características que apresentem maior coeficiente de repetibilidade, exigindo, conseqüentemente, um menor número de medições para predizer o valor real de uma determinada característica (Tabela 2).

O método dos componentes principais, baseado na matriz de covariância $\left(\mathrm{CP}_{\text {cov }}\right)$, apresentou maiores valores de coeficientes de repetibilidade em relação a todas as características, nas duas épocas de cultivo, com exceção da relação MNB, na segunda época, cujo valor observado no método dos componentes principais, com base na matriz de correlações $\left(\mathrm{CP}_{\text {cor }}\right)$, foi maior. Por sua vez, as estimativas dos coeficientes de repetibilidade obtidos pelos métodos da análise de variância (ANOVA) e análise estrutural, com base na matriz de correlações intraclasse $\left(\mathrm{AE}_{\mathrm{cor}}\right)$ e matriz de variâncias e covariâncias $\left(\mathrm{AE}_{\mathrm{cov}}\right)$, apresentaram valores baixos e negativos em todas as variáveis, com exceção da relação MNB nas duas épocas de cultivo (Tabela 3). Estimativas negativas de coeficientes de repetibilidade e, por consequiência, do coeficiente de determinação, em relação à massa de frutos danificados na segunda época, são decorrentes da nãosignificância do efeito de genótipos e estimativas negativas da variância genética. Deve-se, então, interpretálos como nulos, sem repetibilidade. Esses resultados corroboram os de Abeywardena (1972), ao relatar que a estimativa mais adequada do coeficiente de repetibilidade, quando os genótipos apresentam comportamento cíclico ao longo das avaliações em relação ao caráter estudado, é a obtida pelo método baseado nos componentes principais. Em muitas espécies, a produção ocorre de forma oscilante, havendo grande variabilidade de produção entre colheitas. Como este efeito pode variar em modo e intensidade entre os genótipos, a análise de variância, utilizada para estimar o coeficiente de repetibilidade, pode não eliminar este componente adicional do erro experimental e, conseqüentemente, o estimador de repetibilidade estaria subestimado (Cruz \& Regazzi, 1997).

Pelo método dos $\mathrm{CP}_{\text {cov }}$, todas as características nas duas épocas apresentam valores altos do coeficiente de repetibilidade, indicando regularidade da superioridade dos genótipos de uma colheita para outra e, conseqüentemente, necessidade de menor número de colheitas para realizar a seleção. Além disso, considerando que algumas dessas características estão correlacionadas linearmente entre si, a $1 \%$ de probabilidade, a seleção indireta de genótipos superiores seria uma alternativa adequada (Tabela 2).

$\mathrm{Na}$ média das características em cada época de cultivo, o coeficiente de repetibilidade, obtido pelo método

Tabela 2. Média dos caracteres massa de frutos bons (MFB), número de frutos bons (NFB), relação MFB/NFB (MNB), massa de frutos danificados (MFD), número de frutos danificados (NFD) e relação MFD/NFD (MND) e estimativa do coeficiente de correlação de Pearson entre os caracteres de genótipos de tomateiro avaliados em duas épocas de cultivo.

\begin{tabular}{|c|c|c|c|c|c|c|c|c|c|}
\hline \multirow[t]{3}{*}{ Caracteres } & \multicolumn{4}{|c|}{ Genótipos (médias das colheitas) } & \multicolumn{5}{|c|}{ Caracteres (correlação simples) } \\
\hline & \multicolumn{9}{|c|}{ Primeira época (transplante em 3/10/2002) } \\
\hline & Empire & Fanny & Floradade & Olympo & NFB & MNB & & & \\
\hline $\operatorname{MFB}\left(\mathrm{g} \mathrm{m}^{-2}\right)$ & 820,312 & 742,082 & 773,201 & 590,677 & $0,917 * *$ & 0,066 & & & \\
\hline $\mathrm{NFB}\left(\right.$ frutos $\mathrm{m}^{-2}$ ) & 5,077 & 6,592 & 6,711 & 3,613 & & $-0,276$ & & & \\
\hline \multirow[t]{3}{*}{ MNB $\left(\mathrm{g}^{\text {fruto }}{ }^{-1}\right)$} & 163,141 & 113,690 & 115,433 & 166,016 & & & & & \\
\hline & \multicolumn{9}{|c|}{ Segunda época (transplante em $28 / 2 / 2003$ ) } \\
\hline & Empire & Rodas & Floradade & Olympo & NFB & MNB & MFD & NFD & MND \\
\hline $\operatorname{MFB}\left(\mathrm{g} \mathrm{m}^{-2}\right)$ & 412,761 & 456,950 & 284,176 & 375,859 & $0,893 * *$ & $0,554 * *$ & $0,755 * *$ & $0,699 * *$ & $0,725 * *$ \\
\hline $\mathrm{NFB}\left(\right.$ frutos $\mathrm{m}^{-2}$ ) & 2,752 & 2,717 & 2,924 & 2,094 & & 0,263 & $0,651 * *$ & $0,690 * *$ & $0,525 * *$ \\
\hline MNB $\left(\mathrm{g} \mathrm{fruto}^{-1}\right)$ & 134,029 & 163,570 & 82,762 & 164,308 & & & $0,456 * *$ & $0,314 *$ & $0,583 * *$ \\
\hline $\operatorname{MFD}\left(\mathrm{g} \mathrm{m}^{-2}\right)$ & 50,853 & 52,409 & 47,050 & 55,889 & & & & $0,934 * *$ & $0,837 * *$ \\
\hline $\mathrm{NFD}\left(\right.$ frutos $\mathrm{m}^{-2}$ ) & 0,501 & 0,395 & 0,606 & 0,422 & & & & & $0,682 * *$ \\
\hline MND ( $\mathrm{g}$ fruto $^{-1}$ ) & 66,180 & 80,057 & 51,023 & 82,748 & & & & & \\
\hline
\end{tabular}

$*$ e **Significativo a $5 \%$ e a $1 \%$ de probabilidade, respectivamente, pelo teste t, com 42 e 54 graus de liberdade para a primeira e segunda época, respectivamente. 
dos $\mathrm{CP}_{\text {cov }}$, foi 0,73 na primeira época e 0,64 na segunda, revelando a necessidade de menor número de colheitas na primeira época, na identificação de genótipos superiores. Na primeira época, a variável massa de frutos bons não apresentou diferença significativa entre os genótipos (Tabela 1). Sendo assim, pode-se inferir que, apesar do menor número de colheitas necessárias na primeira época (maior repetibilidade das características), a identificação de genótipos promissores nessa época, quanto a esta variável, fica prejudicada pela não-manifestação de diferenças significativas. Isso pode ser explicado pelas condições meteorológicas mais favoráveis ao desenvolvimento dos genótipos nesta época, que puderam, assim, manifestar todo o seu potencial. Por sua vez, na segunda época, as condições meteorológicas menos favoráveis podem explicar a manifestação de diferenças significativas entre os genótipos. Como alternativa, a escolha de genótipos superiores na primeira época de

Tabela 3. Estimativas dos coeficientes de repetibilidade $(\hat{\mathrm{r}})$, dos coeficientes de determinação $\left(\mathrm{R}^{2}\right)$ e do número de medições ou colheitas $\left(\eta_{0}\right)$ associado a diferentes coeficientes de determinação $\left(\mathrm{R}^{2}\right)$ dos caracteres massa de frutos bons (MFB), número de frutos bons (NFB), relação MFB/NFB (MNB), massa de frutos danificados (MFD), número de frutos danificados (NFD) e relação MFD/NFD (MND) de genótipos de tomateiro, avaliados em duas épocas de cultivo, considerando diferentes métodos.

\begin{tabular}{|c|c|c|c|c|c|c|c|c|c|c|}
\hline \multirow[t]{2}{*}{ Método $^{(1)}$} & \multirow[t]{2}{*}{ Estimativas } & \multicolumn{3}{|c|}{$\begin{array}{c}\text { Primeira época } \\
\text { Transplante em } 3 / 10 / 2002\end{array}$} & \multicolumn{6}{|c|}{$\begin{array}{c}\text { Segunda época } \\
\text { Transplante em } 28 / 2 / 2003\end{array}$} \\
\hline & & MFB & NFB & MNB & MFB & NFB & MNB & MFD & NFD & MND \\
\hline \multirow[t]{7}{*}{ ANOVA } & $\hat{\mathrm{r}}$ & 0,059 & 0,266 & 0,783 & 0,299 & 0,121 & 0,704 & $-0,016$ & 0,176 & 0,314 \\
\hline & $\mathrm{R}^{2}(\%)$ & 40,96 & 79,96 & 97,54 & 85,67 & 65,86 & 97,09 & $-28,53$ & 74,89 & 86,48 \\
\hline & $\eta_{\mathrm{o}}\left(\mathrm{R}^{2}=0,80\right)$ & 63 & 11 & 1 & 9 & 29 & 2 & $-252^{(2)}$ & 19 & 9 \\
\hline & $\eta_{0}\left(\mathrm{R}^{2}=0,85\right)$ & 90 & 16 & 2 & 13 & 41 & 2 & $-357^{(2)}$ & 27 & 12 \\
\hline & $\eta_{\mathrm{o}}\left(\mathrm{R}^{2}=0,90\right)$ & 143 & 25 & 2 & 21 & 65 & 4 & $-568^{(2)}$ & 42 & 20 \\
\hline & $\eta_{0}\left(R^{2}=0,95\right)$ & 301 & 52 & 5 & 45 & 138 & 8 & $-1.198^{(2)}$ & 89 & 42 \\
\hline & $\eta_{0}\left(\mathrm{R}^{2}=0,99\right)$ & 1.570 & 273 & 27 & 232 & 718 & 42 & $-6.244^{(2)}$ & 465 & 217 \\
\hline \multirow[t]{7}{*}{$\mathrm{CP}_{\mathrm{cov}}$} & $\hat{\mathrm{r}}$ & 0,679 & 0,633 & 0,886 & 0,596 & 0,623 & 0,758 & 0,550 & 0,737 & 0,567 \\
\hline & $\mathrm{R}^{2}(\%)$ & 95,87 & 95,00 & 98,84 & 95,39 & 95,86 & 97,77 & 94,47 & 97,51 & 94,82 \\
\hline & $\eta_{\mathrm{o}}\left(\mathrm{R}^{2}=0,80\right)$ & 2 & 2 & 1 & 3 & 2 & 1 & 3 & 1 & 3 \\
\hline & $\eta_{\mathrm{o}}\left(\mathrm{R}^{2}=0,85\right)$ & 3 & 3 & 1 & 4 & 3 & 2 & 5 & 2 & 4 \\
\hline & $\eta_{\mathrm{o}}\left(\mathrm{R}^{2}=0,90\right)$ & 4 & 5 & 1 & 6 & 5 & 3 & 7 & 3 & 7 \\
\hline & $\eta_{\mathrm{o}}\left(\mathrm{R}^{2}=0,95\right)$ & 9 & 11 & 2 & 13 & 11 & 6 & 16 & 7 & 15 \\
\hline & $\eta_{0}\left(R^{2}=0,99\right)$ & 47 & 57 & 13 & 67 & 60 & 32 & 81 & 35 & 76 \\
\hline \multirow[t]{7}{*}{$\mathrm{CP}_{\text {cor }}$} & $\hat{\mathrm{r}}$ & 0,409 & 0,593 & 0,809 & 0,477 & 0,523 & 0,812 & 0,464 & 0,453 & 0,457 \\
\hline & $\mathrm{R}^{2}(\%)$ & 88,41 & 94,13 & 97,89 & 92,73 & 93,89 & 98,37 & 92,36 & 92,05 & 92,19 \\
\hline & $\eta_{\mathrm{o}}\left(\mathrm{R}^{2}=0,80\right)$ & 6 & 3 & 1 & 4 & 4 & 1 & 5 & 5 & 5 \\
\hline & $\eta_{\mathrm{o}}\left(\mathrm{R}^{2}=0,85\right)$ & 8 & 4 & 1 & 6 & 5 & 1 & 7 & 7 & 7 \\
\hline & $\eta_{\mathrm{o}}\left(\mathrm{R}^{2}=0,90\right)$ & 13 & 6 & 2 & 10 & 8 & 2 & 10 & 11 & 11 \\
\hline & $\eta_{0}\left(R^{2}=0,95\right)$ & 27 & 13 & 5 & 21 & 17 & 4 & 22 & 23 & 23 \\
\hline & $\eta\left(R^{2}=0,99\right)$ & 143 & 68 & 23 & 109 & 90 & 23 & 115 & 120 & 117 \\
\hline \multirow[t]{7}{*}{$\overline{\mathrm{AE}_{\mathrm{cov}}}$} & $\hat{\mathrm{r}}$ & 0,059 & 0,266 & 0,783 & 0,299 & 0,121 & 0,704 & $-0,016$ & 0,176 & 0,314 \\
\hline & $\mathrm{R}^{2}(\%)$ & 40,96 & 79,96 & 97,54 & 85,67 & 65,86 & 97,09 & $-28,53$ & 74,89 & 86,48 \\
\hline & $\eta_{\mathrm{o}}\left(\mathrm{R}^{2}=0,80\right)$ & $-(3)$ & - & - & - & - & - & - & - & - \\
\hline & $\eta_{\mathrm{o}}\left(\mathrm{R}^{2}=0,85\right)$ & - & - & - & - & - & - & - & - & - \\
\hline & $\eta_{\mathrm{o}}\left(\mathrm{R}^{2}=0,90\right)$ & - & - & - & - & - & - & - & - & - \\
\hline & $\eta_{\mathrm{o}}\left(\mathrm{R}^{2}=0,95\right)$ & - & - & - & - & - & - & - & - & - \\
\hline & $\eta_{\mathrm{o}}\left(\mathrm{R}^{2}=0,99\right)$ & - & - & - & - & - & - & - & - & - \\
\hline \multirow[t]{7}{*}{$\overline{\mathrm{AE}_{\text {cor }}}$} & $\hat{\mathrm{r}}$ & 0,007 & 0,374 & 0,793 & 0,368 & 0,108 & 0,803 & $-0,010$ & 0,032 & 0,336 \\
\hline & $\mathrm{R}^{2}(\%)$ & 6,82 & 86,81 & 97,68 & 89,09 & 62,81 & 98,27 & $-15,25$ & 31,35 & 87,64 \\
\hline & $\eta_{\mathrm{o}}\left(\mathrm{R}^{2}=0,80\right)$ & 601 & 7 & 1 & 7 & 33 & 1 & $-423^{(2)}$ & 123 & 8 \\
\hline & $\eta_{\mathrm{o}}\left(\mathrm{R}^{2}=0,85\right)$ & 851 & 9 & 1 & 10 & 47 & 1 & $-599^{(2)}$ & 174 & 11 \\
\hline & $\eta_{\mathrm{o}}\left(\mathrm{R}^{2}=0,90\right)$ & 1.352 & 15 & 2 & 15 & 75 & 2 & $-952^{(2)}$ & 276 & 18 \\
\hline & $\eta_{\mathrm{o}}\left(\mathrm{R}^{2}=0,95\right)$ & 2.854 & 32 & 5 & 33 & 158 & 5 & $-2.010^{(2)}$ & 582 & 38 \\
\hline & $\eta_{\mathrm{o}}\left(\mathrm{R}^{2}=0,99\right)$ & 14.870 & 165 & 26 & 170 & 821 & 24 & $-10.472^{(2)}$ & 3.035 & 195 \\
\hline
\end{tabular}

(1)ANOVA: análise de variância; $\mathrm{CP}_{\text {cov }}$ : componentes principais das variâncias e covariância; $\mathrm{CP}_{\text {cor }}$ : componentes principais das correlações; $\mathrm{AE}_{\mathrm{cov}}$ : análise estrutural das covariância; $\mathrm{AE}_{\mathrm{cor}}$ : análise estrutural das correlações. ${ }^{2}$ Estimativas negativas devido ao quadrado médio de genótipos ser menor que o quadrado médio do resíduo. ${ }^{(3)}$ Estimativas não calculadas por este método. 
cultivo em relação à massa de frutos bons poderia ser realizada indiretamente por meio do número de frutos bons, pois apresentam alta correlação linear significativa (Tabela 2).

Pelo método $\mathrm{CP}_{\text {cov }}$, para estimar o coeficiente de repetibilidade, pode-se selecionar genótipos superiores com precisão de $90 \%$, em relação às características MFB, NFB e MNB, com até cinco e seis colheitas, para a primeira e segunda época de cultivo, respectivamente (Tabela 3). Já em relação às características associadas a frutos danificados (MFD, NFD e MND), necessita-se de até sete colheitas para escolher genótipos superiores. Estes resultados são coerentes aos obtidos, para tomate do tipo salada sob estufas de plástico, por Lopes et al. (1998), que verificaram que a colheita acumulada até, aproximadamente, $33 \%$ da produção total estimada é suficiente para a discriminação entre tratamentos, pois nesta fase se encontra a menor diferença mínima significativa entre os mesmos.

\section{Conclusão}

Sete colheitas são suficientes para identificar genótipos superiores em relação às características de produção do tomate.

\section{Agradecimento}

Ao Conselho Nacional de Desenvolvimento Científico e Tecnológico, pela concessão de bolsa a Lindolfo Storck.

\section{Referências}

ABEYWARDENA, V. An application of principal component analysis in genetics. Journal of Genetics, v.61, p.27-51, 1972.

CARVALHO, C.G.P. de. Repetibilidade e seleção de híbridos de cacaueiro. 1999. 177p. Tese (Doutorado) - Universidade Federal de Viçosa, Viçosa.

CAVALCANTI, J.J.V.; PAIVA, J.R. de; BARROS, L. de M.; CRISÓSTOMO, J.R.; CORREAA, M.P.F. Repetibilidade de caracteres de produção e porte da planta em clones de cajueiro-anão precoce. Pesquisa Agropecuária Brasileira, v.35, p.773-777, 2000.

CORNACCHIA, G.; CRUZ, C.D.; PIRES, I.E. Estimativa do coeficiente de repetibilidade para características fenotípicas de procedências de Pinus tecunumanii (Schw.) Eguiluz \& Perry e Pinus caribaea var. hondurensis Barret \& Golfari. Revista Árvore, v.19, p.333-345, 1995.

COSTA, J.G.; LEDO, A.S.; OLIVEIRA, M.N. Estimativas de repetibilidade de características de frutos de cupuaçuzeiro no Estado do Acre. Revista Brasileira de Fruticultura, v.19, p.313-318, 1997.

CRUZ, C.D. Programa GENES- versão Windows: aplicativo computacional em genética e estatística. Viçosa: UFV, 2001. 648p.

CRUZ, C.D.; REGAZZI, A.J. Modelos biométricos aplicados ao melhoramento genético. 2.ed. Viçosa: UFV, 1997. 390p.

DIAS, L.A. dos S.; KAGEYAMA, P.Y. Repeatability and minimum harvest period of cacao (Theobroma cacao L.) in Southern Bahia. Euphytica, v.102, p.29-35, 1998.

FERREIRA, R. de P.; BOTREL, M. de A.; PEREIRA, A.V.; CRUZ, C.D. Avaliação de cultivares de alfafa e estimativas de repetibilidade de caracteres forrageiros. Pesquisa Agropecuária Brasileira, v.34, p.995-1002, 1999.

KEMPTHORNE, O. An introduction to genetic statistics. $2^{\text {nd }}$ ed. Ames: Iowa State University, 1973. 545p.

LOPES, R.; BRUCKNER, C.H.; CRUZ, C.D.; LOPES, M.T.G.; FREITAS, G.B. de. Repetibilidade de características do fruto de aceroleira. Pesquisa Agropecuária Brasileira, v.36, p.507-513, 2001.

LOPES, S.J.; STORCK, L.; HELDWEIN, A.B.; FEIJÓ, S.; ROS, C.A. da. Técnicas experimentais para tomateiro tipo salada sob estufas plásticas. Ciência Rural, v.28, p.193-197, 1998.

MANSOUR, H.; NORDHEIM, E.V.; RUTLEDGE, J.J. Estimators of repeatability. Theoretical and Applied Genetics, v.60, p.151156, 1981.

OLIVEIRA, M.S.P.; FERNANDES, G.L.C. Repetibilidade de caracteres do cacho de açaizeiro nas condições de Belém-PA. Revista Brasileira de Fruticultura, v.23, p.613-616, 2001.

PEREIRA, A.V.; FERREIRA, R. de P.; CRUZ, C.D.; FREITAS, V.P.; OLIVEIRA, P.T.A. de. Comportamento de alfafa cv. Crioula de diferentes origens e estimativas dos coeficientes de repetibilidade para caracteres forrageiros. Revista Brasileira de Zootecnia, v.27, p.686-690, 1998.

RADIN, B. Eficiência de uso da radiação fotossinteticamente ativa pelo tomateiro cultivado em diferentes ambientes. 2002. 127p. Tese (Doutorado) - Universidade Federal do Rio Grande do Sul, Porto Alegre.

RUTLEDGE, J.J. A scaling which removes bias of Abeywardena's estimator of repeatability. Journal of Genetics, v.61, p.247-250, 1974.

SHIMOYA, A.; PEREIRA, A.V.; FERREIRA, R. de P.; CRUZ, C.D.; CARNEIRO, P.C.S. Repetibilidade de características forrageiras do capim-elefante. Scientia Agricola, v.59, p.227-234, 2002.

VASCONCELLOS, M.E. da C.; GONÇALVES, P. de S.; PAIVA, J.R. de; VALOIS, A.C.C. Métodos de estimação do coeficiente de repetibilidade no melhoramento da seringueira. Pesquisa Agropecuária Brasileira, v.20, p.433-437, 1985.

Recebido em 30 de março de 2004 e aprovado em 30 de agosto de 2004 